\title{
El cine como elemento didáctico para explicar el terrorismo
}

\author{
Diego ITURRIAGA BARCO \\ Universidad de La Rioja \\ diego.iturriaga@unirioja.es
}

\begin{abstract}
Resumen
En este artículo se pretende analizar en primer lugar las películas que abordan de forma directa el terrorismo fundamentalista e igualmente aquellas que introducen nuevas visiones sobre este elemento que, sin lugar a dudas, ha cambiado el presente de todos los ciudadanos y, por tanto, también de los estudiantes de primaria, que serían los perceptores finales de este proyecto de explicación de la realidad que les ha tocado vivir.
\end{abstract}

Palabras clave: Cine, terrorismo, Al Qaeda, primaria.

\section{Watching films as a didactic element to explain terrorism}

\begin{abstract}
This article aims to analyze the movies directly addressed fundamentalist terrorism and equally those that introduce new insights on this item, without doubt, has changed the present for all citizens and, also for elementary students, which would be the final recipients of this proposed explanation of the reality they live.
\end{abstract}

Keywords: Films, Terrorism, Al Qaeda, Primary Education.

Referencia normalizada:

Iturriaga Barco, D. (2013) El cine como elemento didáctico para explicar el terrorismo. Historia y Comunicación Social. Vol. 18. № Especial Noviembre. Págs. 757-765.

Sumario: 1. La utilización del cine en nuestras aulas. 2. Qué objetivos buscamos. 3. La introducción de visionado de películas en el aula. 4. El cine tras los atentados del 11 de septiembre. 5. El cine de ficción y su relación con el 11-S. 6. El cine que vendrá... 7. Conclusiones. 8. Bibliografía.

\section{La utilización del cine en nuestras aulas}

La realidad docente, a todos los niveles, es quizás hoy más compleja que nunca. Jamás han existido más oportunidades que ahora, nunca ha habido más recursos, contamos con la en teoría generación de jóvenes españoles más y mejor preparados... pero la realidad en el día a día en el aula desprende otras conclusiones. Y es que sin creer el tópico de que "cualquier tiempo pasado fue mejor" parece que la cultura general de nuestros jóvenes (entiéndase como concepto extenso: primaria, secun- 
daria, universidad) deja mucho que desear, idea repetida por todo tipo de docentes. ¿Causas? ¿Culpables? Pregunta sencilla... pero respuesta compleja por lo amplia que puede llegar a ser: y es que podemos culpar al sistema educativo, a la enésima reforma educativa a todos los niveles, a la mala praxis de muchos docentes, al papel de los padres en la educación de sus hijos, e incluso a la posmodernidad deshumanizada que nos ha tocado vivir.

Jamás una generación como la actual ha tenido tantos estímulos audiovisuales como la actual. Tenemos que percatarnos que en la actual sociedad se ofrece mucha más información que la que podemos asumir como seres humanos. Por tanto parece fundamental el desarrollo de la capacidad de discriminación en nuestros alumnos para que sean capaces de separar lo válido del "ruido".

En este contexto, debemos debatir el papel de la imagen en general y del cine en particular como herramienta de trabajo en nuestras aulas. ¿Tiene sentido que las clases carezcan de medios audiovisuales y tecnológicos absolutamente cotidianos en el día a día del alumnado? ¿No es posible trabajar con ordenadores, tabletas, redes sociales y generar conocimiento? ¿No podemos decir algo parecido de la televisión, las series o el cine?

Creo que todos podemos afirmar que la utilización del cine en el aula despierta el interés del alumnado. Y si es así, ¿por qué no lo utilizamos más? Veamos en este sentido cómo podríamos trabajar un elemento cotidiano como puede ser el terrorismo fundamentalista a través de las producciones cinematográficas.

\section{Qué objetivos buscamos}

Variados pueden ser los objetivos que busquemos con la utilización, visionado y análisis de películas sobre terrorismo. Resaltemos algunos de ellos:

- Análisis de la situación actual mundial. A partir de los atentados del 11 de septiembre de 2001 en Estados Unidos, un nuevo actor va a hacerse presente en nuestras sociedades occidentales: Al Qaeda, el principal grupo terrorista fundamentalista del planeta. En términos históricos, el período de tiempo pasado desde entonces es minúsculo, pero la presencia de dicho grupo terrorista y sus células adyacentes han marcado, en parte, el devenir de muchos estados occidentales.

- Afianzar conocimientos, generar otros nuevos y conocer nuevas realidades y perspectivas sobre el fenómeno del terrorismo globalizado.

- Desarrollar el interés del alumnado por un fenómeno de estricta actualidad.

- Fomentar el espíritu crítico de los estudiantes, intentado fomentar debates racionales a partir de la ficción vista en pantalla y su relación con la realidad.

- Trabajar actitudes como la empatía tanto sobre situaciones reales pasadas como sobre futuros posibles o probables. 
- Generar debate en el aula, donde el alumnado tendría que posicionarse e incluso llegar a buscar explicaciones (que no justificar) a los atentados terroristas pasados y conocidos por todos.

- Propiciar una visión crítica respecto a la tergiversación o demagogia que parte del mundo audiovisual puede tener sobre un hecho puntual (en este caso, sobre el nuevo enemigo del siglo XXI tras la caída del comunismo: el terrorismo fundamentalista).

- Conocer otro tipo de cine, más alejado de los blockbusters omnipresentes en las salas de nuestras ciudades y propiciar, de alguna forma, la apertura de mente hacia nuevos productos culturales menos comerciales.

- Hacer ver al alumnado que sus prejuicios ante un hecho o un fenómeno no siempre son los correctos.

- Confrontar la realidad con "la realidad cinematográfica", lo que constituye un elemento de refuerzo pedagógico positivo.

- Exponer sus conclusiones en público, fomentando su visión crítica propia y respecto a los demás.

\section{La introducción del visionado de películas en el aula}

Una de las críticas más habituales a la utilización del cine en el aula pasa porque la proyección simplemente es una herramienta para llenar tiempo de clase o para "entretener" al alumnado. Y no debemos engañarnos, ya que, a veces, realmente es así. Es decir, si creemos en el uso didáctico del cine no nos podemos limitar a reproducir sus imágenes, sino que debe haber un trabajo previo por parte del profesor y de los estudiantes.

Un trabajo que debe pasar por la creación de, al menos, dos guías: una guía del profesor, con las instrucciones de utilización, las soluciones a las cuestiones planteadas en las actividades, orientaciones metodológicas y una selección de los cortes a trabajar (en caso de que no se vaya a visualizar la película por completo); y una guía del alumno con las explicaciones clave sobre lo que esperamos trabajar en la sesión.

¿Qué debemos incluir en estas guías? Fundamental es la ficha técnica de la película que vamos a trabajar. Una ficha técnica que debe incluir, al menos, los siguientes ítems: título, Tráiler, duración, nacionalidad y fecha de creación, sinopsis, director, género, y otros elementos (distribuidora, palmarés, crítica experta, etc.). Posteriormente debemos pararnos en analizar la historia que se nos cuenta, haciendo especial hincapié en el tema de la película, el argumento, los personajes y si lo creemos oportuno en el sonido, el montaje, etc.

Y todo ello sin olvidarnos de las actividades tanto previas como posteriores al visionado de la película. En un primer momento podemos analizar el título, el cartel, la sinopsis, elaborar hipótesis sobre la trama, sus personajes, etc. En esta primera fase 
nuestro objetivo tiene que pasar por captar el interés del alumnado hacia la película que vamos a trabajar.

Durante el visionado podremos establecer preguntas para comprobar que los espectadores están siguiendo de forma correcta la película. En función del nivel educativo del alumnado y de la dificultad de la película estas interrupciones se pueden dar más a menudo o, en su caso, eliminar.

Y, finalmente, hablaríamos de las actividades a realizar tras el visionado, donde primarían actividades comunicativas, tanto orales como escritas. De esta forma, se debe pretender utilizar lo aprendido y asentar conocimientos. Dichas actividades, tanto orales como escritas, buscan la implicación de los estudiantes ya sea en ejercicios autónomos o en grupo, donde se desarrollen tanto la dimensión cognitiva como la afectiva.

\section{El cine tras los atentados del 11 de septiembre}

11 de septiembre de 2001. Nueva York. Las cámaras de los informativos, que estaban en la zona cubriendo la noticia de un primer impacto contra la Torre Sur del World Trade Center dieciocho minutos antes, recogieron y transmitieron en directo las dramáticas imágenes para todo el mundo. La reacción fue general y global: incredulidad, miedo, estupor... y, sobre todo, sorpresa, al menos hasta cierto punto. El hecho sorprendía por lo atroz de sus dimensiones. Todos nos decíamos que era la primera vez que veíamos algo así... al menos en la realidad y a pesar de ello ya los habíamos "visto", sólo que a través del cine. De hecho, el comentario aquel día era coincidente: parece una escena sacada de una película de Hollywood. La industria hollywoodiense nos había acostumbrado a imágenes como las que estábamos apreciando en directo. Quizás la diferencia entre las escenas de Hollywood y las escenas del 11 de septiembre fue la que hay entre la ficción y la realidad, que en numerosas ocasiones se confunden. Lo cierto, lo real en esta ocasión, era que las imágenes no habían sido preparadas por un productor, un director o unos técnicos en efectos especiales.

Con el 11 de septiembre, además de unirse más que nunca las líneas entre ficción cinematográfica y realidad, también ocurre otro hecho interesante: la representación mediática de la realidad quedaba condicionada por nuestro bagaje cinematográfico, influenciando de manera directa tanto en la forma de testimoniar y transmitir los hechos como en el de percibirlos por parte de los espectadores.

Si partimos de la propia ejecución de los atentados a partir de las imágenes que todos recordamos y que forman ya parte de nuestro imaginario colectivo, tenemos que destacar que nos encontramos ante un acontecimiento eminentemente visual. Esto no es algo nuevo para los grupos terroristas fundamentalistas ya que está dentro de la lógica del terror que ellos propagan, donde lo que se busca es el vehículo más 
potente y directo para transmitir su mensaje. Y ese vehículo es la imagen en sí misma: esta se convierte en la propia ideología.

¿Está el público de hoy preparado para ver películas que recrean de una manera u otra los atentados de EE.UU. del 11 de septiembre de 2001? ¿Lo están nuestros alumnos? Un debate que surge cuando se presenta United 93 de Paul Greengrass y que aún hoy despierta encontradas opiniones. Antes de esta película, no encontramos ninguna otra que aborde de manera directa los atentados. Al menos no en EE.UU. En este sentido tenemos que recordar la obra coral 11'09"01, producción francesa articulada por varios cortometrajes de autoría colectiva que encaró el atentado con urgencia. En contraposición llama la atención el olvido o evasión de las productoras cinematográficas de afrontar los hechos de 2001 de una forma directa, más allá de películas puntuales como World Trade Center de Oliver Stone o la reciente Tan fuerte, tan cerca, de Stephen Daldry.

\section{El cine de ficción y su relación con el 11-sel cine de ficción y su relación con el 11-s}

Es curioso ver cómo hasta el año 2006 no había sido estrenado ningún film de ficción que recreara lo sucedido aquel 11 de septiembre. Desde aquel día ya se habló de la posibilidad de que Hollywood o cualquier otra parte de la industria del cine mundial abordara, más tarde o más temprano, los atentados en forma de ficción. El problema no era tanto el cómo sino el cuándo. Las ideas y los guiones estaban sobre la mesa pero nadie quería adelantarse con los estrenos de una serie de películas que podrían herir la sensibilidad del público, en particular del estadounidense, traumatizado por la tragedia del World Trade Center y, por ende, dañar los resultados de taquilla. Sin embargo, la historia del cine muestra cómo la industria cinematográfica estadounidense siempre ha tendido a recoger en fotogramas la historia reciente no sólo de su país sino de todo el planeta por lo que el estreno de películas sobre el 11-S sólo era cuestión de tiempo.

\subsection{United 93}

La película es una dramatización que, a modo de crónica, describe los acontecimientos que tuvieron lugar dentro del aparato así como en diversos centros de control aéreo, tanto civiles como militares. Greengrass adopta una voluntad descriptiva en esta película, casi a modo de documental, dejando de lado enjuiciamientos o planteamientos de novedades. Lo fundamental radica en la voluntad de los seres humanos secuestrados, quienes siempre según la versión del gobierno estadounidense impidieron que los secuestradores impactaran el avión contra la Casa Blanca, convirtiéndose de manera inmediata en héroes nacionales.

United 93 consigue recrear en 106 minutos la supuesta aventura de uno de los aviones secuestrados aquella mañana de septiembre, siendo especialmente meritoria 
su valentía de ser el primer film que aborda sin tapujos la masacre del 11 de septiembre. Aunque con ella, y como no podía ser de otra manera, también llegó la polémica. En este caso, de parte de algunas familias de las víctimas y por el hecho de que la Universal Pictures pudiera ganar dinero con este drama. A este respecto la productora anunció que el $10 \%$ de las ganancias del film se destinarían a la construcción del memorial previsto en honor a las víctimas.

\subsection{World trade center}

Esta película, dirigida por el controvertido Oliver Stone, recrea la historia del rescate de dos policías neoyorquinos, dos de los veinte supervivientes que pudieron ser rescatados de los escombros de las torres gemelas. A diferencia de United 93, World Trade Center sí cuenta con actores de reconocido prestigio como Nicolas Cage, Michael Pena, Maggie Gyllenhaal y Maria Bello. Es la primera película que recrea, en parte, lo sucedido en el World Trade Center neoyorquino aquel 11 de septiembre.

Siempre bajo la premisa del respecto a las víctimas y a sus familiares, al igual que el largometraje de Greengrass, Stone deja de lado las interpretaciones políticas de los atentados del 11-S para recrear únicamente el drama vivido por las víctimas y sus familiares en aquellas horas. El espectador no encontrará reflexión ideológica y sí una versión del lado más humano de la tragedia, centrándose en visiones particulares, algo llamativo teniendo en cuenta la trascendencia global de lo allí ocurrido. Podríamos afirmar que los pilares sustentantes de la película son el sufrimiento, la solidaridad y el sentido del sacrificio. La estética es estrictamente realista, quizás por la proximidad de los acontecimientos lo que impide moralmente la manipulación de cualquier elemento.

Con todo, World Trade Center, es una película convencional pero valiente, cargada en demasía de un profundo heroísmo y un sentido patriótico hasta la médula. No deja de ser un mero homenaje a las víctimas de aquel día, por lo que se echa en falta una mayor carga temática como podría esperarse de un film de Oliver Stone.

\section{El cine que vendrá...}

Con el cambio de siglo y con lo sucedido aquel 11 de septiembre de 2001 (en el que el mundo entraba históricamente en el siglo XXI) la nueva fuente de guiones y películas de Hollywood se encuentra en Oriente Medio, acerca de cuya problemática y consecuencias ya se han acercado todo tipo de directores, productores y actores, no sólo independientes sino también nombres célebres como Robert Redford, Ridley Scott, Jamie Foxx, Leonardo DiCaprio, Matt Damon o Russell Crowe. Hablamos de películas como La sombra del reino (The Kingdom) en el que el FBI investiga un atentado terrorista producido en un complejo residencial occidental en Riad, Arabia Saudí. 
De forma más directa sobre los atentados del 11-S encontramos Rendition en la que se presentan algunas de las consecuencias de la nueva política internacional y de las nuevas medidas de seguridad recortadoras de libertades que rigen nuestra sociedad. Otro título interesante es Gaza, cuya protagonista es Helen Mirren quien interpreta a una madre judía cuya hija, una periodista enamorada de un palestino, es asesinada. Una mirada más personal que política, sobre un drama humano de difícil solución. Como igualmente personal es la mirada de Michael Winterbottom (autor de la extraordinaria Camino a Guantánamo) en Un corazón invencible sobre la desaparición y posterior ejecución del periodista de The Wall Street Journal Daniel Pearl en Pakistán en el año 2002. Películas de perfil personalista, como United 93 o World Trade Center, quizás demasiado particulares teniendo en cuenta la gravedad global de los temas que subyacen, pero que igualmente pueden ser consideradas como necesarias para adentrarnos en el dolor personal de las personas civiles que no dejan de ser los verdaderos damnificados de esta coyuntura.

Igualmente, podemos destacar otros títulos centrados en la Guerra de Irak, como por ejemplo En el valle de Elah de Paul Haggis, En tierra hostil de Kathryn Bigelow, La batalla de Hadiza, de Nick Broomfield y en la que se recrean brutales venganzas reales de algunos marines norteamericanos o Green Zone donde Paul Greengrass vuelve a trabajar con Matt Damon en esta comedia negra sobre la incompetencia del gobierno provisional en Irak impuesto por Bush y sus correligionarios neoconservadores. Con la guerra contra el terrorismo como excusa Tom Cruise volvió a las pantallas en esta ocasión dirigido por Robert Redford en Leones por corderos, un film de historias que se acaban entrecruzando.

Como podemos ver, a pesar de la crisis inminente tras el 11-S, el cine ha sabido adecuar la nueva coyuntura a su industria. Y mientras la taquilla funcione, los guiones continuarán y las películas se rodarán.

\section{Conclusiones}

No parece razonable obviar el poder de la imagen en nuestra sociedad y no darle, por lo tanto, la importancia que tiene día a día en todos nosotros, incluidos nuestros alumnos. Por ello es fundamental que pase a formar parte de la rutina educativa en nuestras aulas a cualquier nivel. Sin lugar a dudas, es una herramienta clave para aquellos docentes casi transgresores y no acomodaticios que quieran sacar lo máximo de su alumnado, despertando su, frecuentemente, dormida creatividad y racionalidad.

Ver una película puede ser simplemente un entretenimiento o puede ser mucho más: puede ser educativo, puede generar apertura de mente... siempre y cuando sepamos trabajar con este recurso y exista un trabajo tanto previo como posterior al central visionado. Los estudiante deben describir lo visto, pero sobre todo deben reflexionar sobre los hechos, las actitudes, deben sacar conclusiones de forma perso- 
nal y en grupo, y tienen que aprender a debatir y defender sus opiniones frente a compañeros y profesores.

Un recurso que debe ser transdisciplinar y que igualmente puede ser utilizado en las diferentes áreas de conocimiento. Difícilmente podremos encontrar un tema o un aspecto del currículo que queramos trabajar sobre el cual no nos podamos apoyar en un recurso audiovisual. En este texto hemos podido reseñar algunas de las principales películas que podrían ser objeto de trabajo para explicar un fenómeno tan actual, y que ha marcado la política exterior occidental de la primera década del siglo XXI hasta el presente, como es el terrorismo yihadista. Películas como United 93, World Trade Center, Tan fuerte, tan cerca, pero también otras no desarrolladas aquí por falta de espacio como Munich, Algunos días en septiembre o Tierras de abundancia o documentales como los de Michael Moore u otros tantos producidos por Canal Historia, National Geographic o Discovery Channel... nos pueden servir de herramientas, más allá de lo que podamos pensar de forma previa, para ver cómo ha sido y cómo se ha mostrado una realidad durante un tiempo que nuestro alumnado ha vivido $\mathrm{y}$, por tanto, es motivo de su atracción.

\section{Bibliografía}

Libros y artículos

BAZO, E. (2003). "Las claves audiovisuales del 11 de septiembre". En Revista Latente, $\mathrm{n}^{\mathrm{o}} 1$, pp. 97-105.

COLLAR J.; PARDO, A. (2006). "Dos miradas al 11S”. En Nuestro Tiempo, $\mathrm{n}^{\circ} 627$, pp. 57-59.

GARCÍA, M. (2004). "Mecanismos de creación de héroes y anti-héroes para la opinión pública internacional en periodos de guerra". En Ámbitos, $\mathrm{n}^{\circ} 11-12$, pp. 39-67.

HUERTA, M. A (2006). Celuloide en llamas. El cine estadounidense tras el 11-S. Madrid: Notorius Ediciones.

QUIRANTES, A. (2012). "Física de película, un ejemplo de cine en la docencia universitaria de primer curso". En Revista electrónica de investigación, Docencia $y$ creatividad, $\mathrm{n}^{\mathrm{o}} 1$, pp. 88-102.

RUFFINELLI, J. (2002). "11 de septiembre: cómo hacer cine en un país devastado". En Casa de las Américas, n 226, pp. 139-143.

SOLÓRZANO, F. (2006). "Septiembre revisitado". En Letras Libres, Septiembre 2006, pp. 96-97.

VV.AA. (2009). Clase de cine. Actividades para la visualización de películas en español. Barcelona: Difusión. 
Páginas web

WEB: El cine, el mundo y los derechos humanos [en línea]. En: Internet: <www. cineddhh.org $>$ [1/12/2012].

WEB: International Movie Data Base [en línea]. En: Internet: <www.imdb.com> [9/12/2012].

WEB: The New York Times [en línea]. En: Internet: <www.thenewyorktimes.com> [12/12/2012].

Películas

DVD: VV.AA., 11'09"01 (2002)

DVD: MOORE, Michael, Fahrenheit 9/11 (2004)

DVD: GREENGRASS, Paul, United 93 (2006)

DVD: STONE, Oliver, World Trade Center (2006)

DVD: DALDRY, Stephen, Tan fuerte, tan cerca (2011)

\section{El autor}

Diego Iturriaga Barco, es doctor en Historia Contemporánea por la Universidad de La Rioja y profesor de la Universidad de La Rioja y de la UNIR. Ha realizado estancias de investigación y cursos de especialización en diferentes centros universitarios entre los que podemos destacar los realizados en la London School of Economics and Political Science, en la Universidad Autónoma de Barcelona y en la Universidad Complutense de Madrid.

Igualmente señalaremos que ha participado en diferentes congresos y ciclos de conferencias con temas como la teorización sobre la historia del tiempo presente, el estudio de la evolución y tendencias de la sociedad riojana en las cuatro últimas décadas, el terrorismo yihadista y el uso didáctico de la imagen en la docencia. 